\title{
Simple Spectrophotometric Method for the Determination of Sulfur Dioxide by Its Decolorizing Effect on the Peroxovanadate Complex ${ }^{1}$
}

\author{
Mahadevaiah, M. S. Abdul Galil, M. S. Yogendra Kumar, \\ M. A. Sathish, and G. Nagendrappa \\ Department of Chemistry, University of Mysore, Manasagangotri, Mysore 570006, India \\ e-mail: gnagendrappa@yahoo.co.in \\ Received July 14, 2006; in final form, March 7, 2007
}

\begin{abstract}
A simple, rapid, and economical spectrophotometric method is developed for the determination of sulfur dioxide in sugar and air samples. The developed method is based on a red-brown peroxovanadate complex $\left(\lambda_{\max }=470 \mathrm{~nm}\right)$ produced in $2 \mathrm{M}$ sulfuric acid when ammonium metavanadate is treated with hydrogen peroxide. Under fixed concentrations of hydrogen peroxide and ammonium metavanadate, when sodium metabisulfite $\left(\mathrm{Na}_{2} \mathrm{~S}_{2} \mathrm{O}_{5}=2 \mathrm{SO}_{2}\right)$ is added, it preferentially reacts with hydrogen peroxide producing sulfuric acid, and the unreacted hydrogen peroxide then reacts with ammonium metavanadate; therefore, the concentration of sulfur dioxide is directly proportional to a decrease in the concentration of the peroxovanadate complex. The stoichiometric ratio between hydrogen peroxide and ammonium metavanadate as well as the stability constant of the complex are determined by the modified Job's method and the respective values are found to be $1: 1$ and $2.5 \times 10^{4} \mathrm{~mol}^{-1} \mathrm{~L}$, respectively. The system obeys Lambert-Beer's law in the concentration range 3.57-64.26 ppm of sulfur dioxide. The molar absorptivity, correlation coefficient, and Sandell's sensitivity values are found to be $0.649 \times 10^{3} \mathrm{~L} \mathrm{~mol}^{-1} \mathrm{~cm}^{-1}, 0.9908$, and $0.1972 \mu \mathrm{g} \mathrm{cm}^{-2}$, respectively. The method is applied to the determination of sulfur dioxide present in commercial sugars and air samples. The results obtained are reproducible with a standard deviation of $0.02-0.05$. For method validation, sulfur dioxide is also determined separately following the AOAC method for an air sample and the ICUMSA method for commercial sugars. The results obtained by the developed and official methods are in good agreement.
\end{abstract}

DOI: $10.1134 / \mathrm{S} 1061934808030088$

\section{INTRODUCTION}

Sulfur dioxide is one of the most harmful air pollutants [1] as it affects both living organisms and inanimate structures. It has been identified as one of the main causes for increasing the acidification of the environment through the generation of acid rain [2]. Sulfur dioxide and sulfites are widely used as antioxidants and preservatives in the food industry [3] and are also employed in sugar manufacturing for improving the final appearance of the sugar [4]. Although sulfur dioxide is acceptable to the body in low concentrations, in high concentrations, it is found to be harmful [2]. As a consequence [1-4], there is a surge in the interest of developing methods $[5,6]$ for its quantitative determination, for example, titrimetry [7, 8], spectrophotometry [1, 8, 9-11], chemiluminescence [12], fluorimetry [13], flow injection [14], chromatography [15], and also polarographic [16] methods. The determination of sulfur dioxide in air $[5,6,8]$, sugar $[10$, 11], wine [17], and beverage [12, 16, 18] samples are of particular importance.

Sensitive methods [1,8-14], particularly spectrophotometric methods [1,8-11], are preferred over the

\footnotetext{
${ }^{1}$ The text was submitted by the authors in English.
}

volumetric $[6,19]$ as well as other methods [12-16] when sulfur dioxide is in low concentrations, because of its simplicity and cost-effective instrumentation. However, one of the spectrophotometric methods [20] employs rosaniline and formaldehyde, which are considered to be toxic [21]. Another AOAC method [22] requires the use of the dye thymol blue, a known $\mathrm{pH}$ indicator. Obviously, the method requires the strict control of $\mathrm{pH}$ and also suffers from a narrow range of sulfur dioxide determination. Therefore, a new spectrophotometric method for sulfur dioxide is developed in our work. The method is based on the formation of a redbrown peroxovanadate complex [23-25], $\lambda_{\max }=$ $470 \mathrm{~nm}$, from ammonium metavandate and hydrogen peroxide in $2 \mathrm{M}$ sulfuric acid. When sodium metabisulfite $\left(\mathrm{Na}_{2} \mathrm{~S}_{2} \mathrm{O}_{5}=2 \mathrm{SO}_{2}\right)$ is added, it preferentially reacts with hydrogen peroxide, thereby decolorizing the peroxovanadate complex until its concentration is less than that of the complex.

\section{EXPERIMENTAL}

Apparatus. An Elico spectrophotometer, models SL171 and SL177 (Hyderabad, India), with 1-cm 
Determination of sulfur dioxide in different samples

\begin{tabular}{l|c|c|c|c}
\hline \multirow{2}{*}{ Samples } & \multicolumn{2}{|c|}{ Concentration of sulfur dioxide in $\mu \mathrm{g} / \mathrm{mL}( \pm \mathrm{SD})(n=5)$ as found by } & \multicolumn{2}{|c}{$95 \%$ confidence limit values of } \\
\cline { 2 - 5 } & new method & official method & $t$ test & $F$ test \\
\hline Sugar A* & $1.51( \pm 0.02)$ & $1.49( \pm 0.03)$ & 1.58 & 2.25 \\
Sugar B* & $1.63( \pm 0.03)$ & $1.61( \pm 0.05)$ & 1.05 & 2.77 \\
Air & $1.79( \pm 0.05)$ & $1.75( \pm 0.07)$ & 1.26 & 1.96 \\
\hline
\end{tabular}

* Commercial sugars from local market.

matched-optical cells, and an Acculab Digital Balance readable to $0.0001 \mathrm{~g}$ were used.

Reagents. All of the chemicals used were of analytical reagent grade and the water used here refers to distilled water.

Ammonium metavanadate solution, 0.01 M. A weighed amount, $0.2925 \mathrm{~g}$, of ammonium metavanadate was transferred into a clean 200 -mL beaker. It was dissolved in warm water, and cooled. The solution was poured into a $250-\mathrm{mL}$ volumetric flask and diluted to the mark with water.

Hydrogen peroxide solution, $\mathbf{0 . 0 2 5 \%}$. Here, $1 \mathrm{~mL}$ of hydrogen peroxide $(50 \%)$ was transferred into a 50 -mL volumetric flask and diluted to the mark with water. From that, an aliquot, $2.5 \mathrm{~mL}$, was transferred into a $100-\mathrm{mL}$ volumetric flask and diluted to the mark with water. It was standardized further by the permanganate method [26] and found to be $0.025 \%$.

Pure sucrose solution, 10\%. A weighed amount, $100 \mathrm{~g}$, of sulfite-free sucrose was transferred into a 1-L volumetric flask. It was dissolved in water and diluted to the mark with water [20].

Standard sodium metabisulfite solution. A weighed amount, $0.06 \mathrm{~g}$, of sodium metabisulfite was transferred into a $100-\mathrm{mL}$ volumetric flask. It was dissolved in water and diluted to the mark with water. It was standardized further by the iodimetric method [13, 20 ] and found to be $357 \mu \mathrm{g} / \mathrm{mL}$ solution of sulfur dioxide.

Sulfuric acid solution, 2 M. This was prepared by the dilution of concentrated sulfuric acid, $1.98 \mathrm{~g} \mathrm{~cm}^{-3}$, $98 \%$, with water.

Triethanolamine (TEA) $1.5 \%$ solution. This was prepared by dissolving $15 \mathrm{~g}$ of triethanolamine (specific gravity 1.24) in water and diluted to $1 \mathrm{~L}$ with water $[8,22,27]$.

Recommended procedure. A series of labeled $10-\mathrm{mL}$ volumetric flasks were arranged. To each flask, $2 \mathrm{~mL}$ of $0.025 \%$ hydrogen peroxide, aliquots of the test solution containing 3.57-64.26 $\mu \mathrm{g} / \mathrm{mL}(0.1,0.2,0.3$, $0.5,0.7,1.0,1.2,1.5,1.8$, or $2.0 \mathrm{~mL}$ ) of sodium sulfite, $3 \mathrm{~mL}$ of $0.01 \mathrm{M}$ ammonium metavanadate, and $3 \mathrm{~mL}$ of $2 \mathrm{M}$ sulfuric acid were added. The solution in each flask was then diluted to the mark with water. The absorbance of each solution as well as the blank (the same test solution containing no sodium metabisulfite) was measured against water at $470 \mathrm{~nm}$. The calibration graph was constructed by plotting the absorbance values of the (blank-test) solutions against the concentration, $\mu \mathrm{g} / \mathrm{mL}$ sulfur dioxide.

Determination of sulfur dioxide in commercial sugar. A weighed amount, $40 \mathrm{~g}$, of the sugar sample was transferred into a $250-\mathrm{mL}$ beaker. It was dissolved in about $50 \mathrm{~mL}$ of water. The resulting solution was transferred into a $100-\mathrm{mL}$ volumetric flask. About $4 \mathrm{~mL}$ of $0.1 \mathrm{M}$ sodium hydroxide solution was added [20] and diluted to the mark with water. From that, a $1-\mathrm{mL}$ aliquot of this solution and a $0.2-\mathrm{mL} 357 \mu \mathrm{g} / \mathrm{mL}$ sulfur dioxide solution per trial were examined for sulfur dioxide content using the new method as well as by the official method [20].

Determination of sulfur dioxide in an air sample. Here, $35 \mathrm{~mL}$ of a $1.5 \%$ triethanolamine solution were transferred into the flask of air sampling apparatus, and air from outside the room was pumped through the flask for $4 \mathrm{~h}$ at the flow rate of $1.3 \mathrm{~L} / \mathrm{min}$. After the termination of sampling, any loss of the trapping solution due to the evaporation was restored to $35 \mathrm{~mL}$ by adding a $1.5 \%$ TEA solution. From that, a $1-\mathrm{mL}$ aliquot, a $0.2-\mathrm{mL} 357 \mu \mathrm{g} / \mathrm{mL}$ sulfur dioxide solution, and a $2-\mathrm{mL}$ of $0.5 \%$ sulphamic acid were transferred into a $10-\mathrm{mL}$ labeled volumetric flask and the sulfur dioxide content of the solution was determined using the new method as described in the recommended procedure and also by the official method [27].

\section{RESULTS AND DISCUSSION}

The reaction conditions as well as the various experimental parameters affecting the color development and stability of the complex [23-25] were carefully investigated and optimized for the quantitative determination of sulfur dioxide in the sugar and air samples. The experimental variables such as concentrations of ammonium metavanadate, hydrogen peroxide, types of acids, and the order of the reagent addition were optimized. For the comparison of the results, sulfur dioxide was also determined separately following the AOAC method [27] for the air-trapped sample and the ICUMSA method [20] for the commercial sugars. The results obtained for sulfur dioxide both by the developed and the official methods $[20,27]$ are shown in the table. As is seen, the results are in good agreement. 
Therefore, the developed method could be either a substitute to the official methods $[20,27]$ or it could also be an independent method for the determination of sulfur dioxide in the sugar and air samples.

Effect of the concentration of ammonium metavanadate. Six series, each for $3,1.5$, and $0.5 \mathrm{~mL}$ of $0.05 \mathrm{M}$ ammonium metavanadate solutions and 1, 2, and $3 \mathrm{~mL}$ of $0.01 \mathrm{M}$ ammonium metavanadate solutions were arranged. In series $1,2 \mathrm{~mL}$ of $0.025 \%$ hydrogen peroxide, $3 \mathrm{~mL}$ of $0.05 \mathrm{M}$ ammonium metavanadate, $3 \mathrm{~mL}$ of $2 \mathrm{M}$ sulfuric acid, and various volumes $(0.1,0.3,0.5,0.7$, or $1.0 \mathrm{~mL})$ of sodium metabisulfite solutions were added into each flask and diluted to the mark with water. The absorbance of each solution was measured at $470 \mathrm{~nm}$. Similarly, the experiments were also performed, but with 1.5 and $0.5 \mathrm{~mL}$ of $0.05 \mathrm{M}$ ammonium metavanadate solutions, respectively, in series 2 and 3 , and 1,2, and $3 \mathrm{~mL}$ of $0.01 \mathrm{M}$ ammonium metavanadate solutions, respectively, in series 4,5 , and 6 . The regression equations and $r^{2}$ values were calculated for all of the series and found to be, in that order, $y=0.0058 x+0.0262, r^{2}=0.9983 ; y=0.0059 x+$ $0.0109, r^{2}=0.9997 ; y=0.0058 x+0.0046, r^{2}=0.9988$; $y=0.0054 x+0.0237, r^{2}=0.9974 ; y=0.0032 x-$ $0.0300, r^{2}=0.9831$; and $y=0.0057 x+0.0210, r^{2}=1$. Based on these, series 6 involving $3 \mathrm{~mL} 0.01 \mathrm{M}$ ammonium metavanadate solution was selected as the optimal one for its concentration.

Effect of various acids. Four acids, namely, hydrochloric acid, phosphoric acid, sulfuric acid, and acetic acid, were selected. Three series of experiments were performed to understand their effect on the linearity and sensitivity for the effective determination of sulfur dioxide. Three experimental series involving $10-\mathrm{mL}$ volumetric flasks were arranged. In series 1, $2 \mathrm{~mL}$ $0.025 \%$ hydrogen peroxide, $3 \mathrm{~mL} 0.01 \mathrm{M}$ ammonium metavanadate, and $3 \mathrm{~mL} 2 \mathrm{M}$ hydrochloric acid with various volumes $(0.1,0.3,0.5,0.7$, or $1.0 \mathrm{~mL})$ of sodium metabisulfite solutions were added into each flask and diluted to the mark with water. The absorbance of each solution was measured at $470 \mathrm{~nm}$ against water. Similarly, series 2 and 3 were also performed, but with $3 \mathrm{~mL} 2 \mathrm{M}$ phosphoric acid and $3 \mathrm{~mL} 2 \mathrm{M}$ sulfuric acid solutions, respectively. The regression equations and $r^{2}$ values were calculated for all of the series and were found to be: $y=0.0064 x+0.0099, r^{2}=$ $0.9967 ; y=0.0061 x+0.0251, r^{2}=0.9855$; and $y=$ $0.0061 x-0.0037, r^{2}=0.9982$, respectively, for series $1-3$. Based on these values, series 3 , involving $3 \mathrm{~mL}$ of $2 \mathrm{M}$ sulfuric acid, was selected as the optimal one for an acidic medium. Finally, when the experiment was repeated with $3 \mathrm{~mL} 2 \mathrm{M}$ acetic acid, the system failed to immediately produce color.

Effect of the concentration of sulfuric acid. Four series of experiments were performed with 3,2 , and $1 \mathrm{~mL} 2 \mathrm{M}$ sulfuric acid and $3 \mathrm{~mL} 4 \mathrm{M}$ sulfuric acid solutions, respectively, in series 1-4. The regression equations and $r^{2}$ values were calculated for all of the series and were found to be: $y=0.0061 x-0.0037, r^{2}=$ $0.9982 ; y=0.0060 x+0.0154, r^{2}=0.9912 ; y=0.0060 x+$ $0.0185, r^{2}=0.9900$; and $y=0.0054 x+0.0270, r^{2}=$ 0.9819 , respectively, for series $1-4$. Based on these values, series 1, involving $3 \mathrm{~mL} 2 \mathrm{M}$ sulfuric acid, was selected as the optimal one for its concentration.

Effect of the concentration of hydrogen peroxide. Like in earlier experiments, three series of experiments were performed, but with 1 and $0.5 \mathrm{~mL} 0.1 \%$ hydrogen peroxide and $3 \mathrm{~mL} 0.025 \%$ hydrogen peroxide solutions, respectively, for series $1-3$. The regression equations and $r^{2}$ values were calculated for all of the series and were found to be: $y=0.0055 x-0.0094, r^{2}=$ $0.9928 ; y=0.0057 x+0.0282, r^{2}=0.994 ;$ and $y=$ $0.0061 x-0.0037, r^{2}=0.9982$, respectively, for series $1-3$. Based on these values, series 3, involving $3 \mathrm{~mL} 0.025 \%$ hydrogen peroxide, was selected as the optimal one for its concentration.

Effect of the order of reagent addition. From the results of the above four experiments involving optimized volumes and concentrations of the reagents, namely, hydrogen peroxide, $2 \mathrm{~mL} 0.025 \%$ (A); ammonium metavanadate, $3 \mathrm{~mL} 0.01 \mathrm{M}(\mathrm{C})$; sulfuric acid, $3 \mathrm{~mL} 2 \mathrm{M}(\mathrm{D})$, were selected for the determination of sulfur dioxide, $0.3 \mathrm{~mL} 357 \mu \mathrm{g} / \mathrm{mL}$ (B). Five experiments were performed corresponding to the order of the reagent addition: $\mathrm{A}+\mathrm{B}+\mathrm{C}+\mathrm{D} ; \mathrm{A}+\mathrm{C}+\mathrm{B}+\mathrm{D} ; \mathrm{B}+$ $\mathrm{D}+\mathrm{C}+\mathrm{A} ; \mathrm{B}+\mathrm{A}+\mathrm{D}+\mathrm{C}$; and $\mathrm{B}+\mathrm{C}+\mathrm{D}+\mathrm{A}$. The absorbance of each solution agreed with those of the other four solutions and also corresponded to an average absorbance value of 0.320 . Hence, the order of the addition of reagents is considered to have no influence on developing the color of the complex [23-25], for which the stability, $K=2.5 \times 10^{4} \mathrm{~mol}^{-1} \mathrm{~L}$, is determined using the modified Job's method [28]. Therefore, it would be possible to assume that hydrogen peroxide either combines with the complex $\mathrm{NH}_{4}\left[\mathrm{VO}\left(\mathrm{O}_{2}\right) \mathrm{SO}_{4}\right]$ stoichiometrically $1: 1$, as determined by Job's method [28], or reacts effectively with sulfur dioxide [29]. To maintain the uniformity of the order of the reagent addition, the order A + B + C + D was followed throughout the course of the sulfur dioxide determination.

Color stability of the complex with time. The color stability of the complex was studied according to the recommended procedure for $25 \mu \mathrm{g} / \mathrm{mL}$ sulfur dioxide. The absorbance of the solution was measured immediately after mixing and also after various intervals of time for two days. Although the color of the system developed immediately after mixing giving the absorbance value 0.414 , the absorbance value 0.333 was attained in $5 \mathrm{~min}$ and found to be stable for two days. The average absorbance is 0.337 (16 measurements).

Calibration graph. Under the optimum experimental conditions, a good linear relationship is found between the absorbance values of the complex solutions and concentrations, 3.57-64.26 $\mu \mathrm{g} / \mathrm{mL}$, of sulfur 


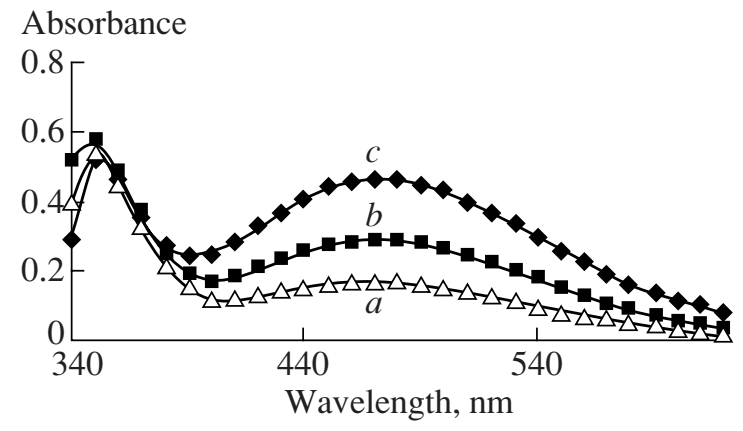

Absorption spectra of the solutions, each containing $2 \mathrm{~mL}$ $0.025 \%$ hydrogen peroxide, (a) $0.1 \mathrm{~mL}\left(3.5 \mu \mathrm{g} \mathrm{mL} \mathrm{m}^{-1}\right)$, (b) $0.7 \mathrm{~mL}\left(35 \mu \mathrm{g} \mathrm{mL}^{-1}\right)$, (c) $2.0 \mathrm{~mL}\left(64.26 \mu \mathrm{g} \mathrm{mL}^{-1}\right)$ of $357 \mu \mathrm{g} \mathrm{mL}^{-1}$ sulfur dioxide, $3 \mathrm{~mL} 0.01 \mathrm{M}$ ammonium metavanadate, $3 \mathrm{~mL} 2 \mathrm{M}$ sulfuric acid, diluted to $10 \mathrm{~mL}$ with water.

dioxide, having a straight line with the slope 0.0047 and intercept -0.0162 . The molar absorptivity, correlation coefficient, and Sandell's sensitivity values were calculated and found to be $0.649 \times 10^{3} \mathrm{~L} \mathrm{~mol}^{-1} \mathrm{~cm}^{-1}, 0.9908$, and $0.1972 \mu \mathrm{g} \mathrm{cm}^{-2}$, respectively.

Precision and accuracy. In order to study the accuracy and precision of the proposed method, three concentrations of sulfur dioxide within the linearity range 3.57, 25.0, and $64.26 \mathrm{ppm}$ (low, medium, and high) were chosen. Intraday precision was studied by using the recommended volumes and concentrations of all of the reagents through five independent analyses. The standard deviation was found to be in the range 0.020.05 . In addition, the accuracy of the new method was also expressed by calculating the relative error, which varies between $-1.33 \%$ and $-0.905 \%$.

Reaction mechanism. The developed method is based on the formation of the red-brown peroxovanadate complex [23-25] with $\lambda_{\max }=470 \mathrm{~nm}$, when ammonium metavanadate is treated with hydrogen peroxide in a sulfuric acid medium:

$$
\begin{aligned}
& \mathrm{H}_{2} \mathrm{O}_{2}+\mathrm{NH}_{4} \mathrm{VO}_{3}+\mathrm{H}_{2} \mathrm{SO}_{4} \\
\longrightarrow & \mathrm{NH}_{4}\left[\mathrm{VO}\left(\mathrm{O}_{2}\right) \mathrm{SO}_{4}\right]+2 \mathrm{H}_{2} \mathrm{O} .
\end{aligned}
$$

The complex is decolorized when sodium metabisulfite or a sample solution containing sulfur dioxide is added to the system, since sulfur dioxide preferentially reacts with hydrogen peroxide producing sulfuric acid [29]:

$$
\mathrm{SO}_{2}+\mathrm{H}_{2} \mathrm{O}_{2} \longrightarrow \mathrm{H}_{2} \mathrm{SO}_{4} \text {. }
$$

Hence, reactions (1) [23-25] and (2) [29] are responsible for the decrease in the concentration of the peroxovanadate complex with an increasing concentration of sulfur dioxide (figure).

Effect of foreign ions. To understand the reaction selectivity, the interference of common ions, which often accompany sulfite and metabisulfite, $\mathrm{Zn}^{2+}, \mathrm{Na}^{+}$, $\mathrm{Cl}^{-}, \mathrm{Cu}^{2+}, \mathrm{Mg}^{2+}, \mathrm{NO}_{2}^{-}$, and $\mathrm{S}^{2-}$, formaldehyde, glucose, and fructose solutions were added and investigated for the determination of $25 \mu \mathrm{g} \mathrm{mL}^{-1}$ sulfur dioxide under the optimum condition as described in the recommended procedure. The ions $\mathrm{Zn}^{2+}\left(\mathrm{ZnSO}_{4} \cdot 7 \mathrm{H}_{2} \mathrm{O}\right), \mathrm{Na}^{+}$ $(\mathrm{NaCl}), \mathrm{Cl}^{-}(\mathrm{NaCl}), \mathrm{Cu}^{2+}\left(\mathrm{CuSO}_{4} \cdot 7 \mathrm{H}_{2} \mathrm{O}\right)$, and $\mathrm{Mg}^{2+}$ $\left(\mathrm{MgSO}_{4}\right)$ were found to not interfere in that order up to 683, 3640, 535.5, and $727 \mu \mathrm{g} \mathrm{mL} \mathrm{m}^{-1}$. But, $\mathrm{NO}_{2}^{-}$ $\left(\mathrm{NaNO}_{2}\right)$ could be tolerated only up to the $2 \mu \mathrm{g} \mathrm{mL} \mathrm{L}^{-1}$ level; however, its interference up to $10 \mu \mathrm{g} \mathrm{mL}^{-1}$ was overcome by the addition of $1 \mathrm{~mL}$ of $1 \%$ sulphamic acid to the sample before analysis [11]. And, $\mathrm{S}^{2-}$ $\left(\mathrm{Na}_{2} \mathrm{~S}\right)$, formaldehyde, and glucose/fructose did not interfere up to 15,107 , and $400 \mu \mathrm{g} \mathrm{mL} \mathrm{m}^{-1}$, respectively.

Application. The new method was used for the determination of sulfur dioxide in the samples of two commercial sugars-sugar A, $1.51 \mu \mathrm{g} \mathrm{mL} \mathrm{m}^{-1}$ (cal., $3.775 \mathrm{mg} / \mathrm{kg}$ ); and sugar $\mathrm{B}, 1.63 \mu \mathrm{g} \mathrm{mL} \mathrm{m}^{-1}$ (cal., $4.075 \mathrm{mg} / \mathrm{kg}$ ) - and one air-trapped sulfur dioxide solution, $1.79 \mu \mathrm{g} / \mathrm{mL}$ (table).

\section{CONCLUSIONS}

The developed method works on the simple and straightforward principles of the reaction between sulfur dioxide and hydrogen peroxide [29] followed by the reaction of unreacted hydrogen peroxide with ammonium metavanadate producing the peroxovanadate complex [23-25], $\lambda_{\max }=470 \mathrm{~nm}$. The method is rapid since the chemicals involved are readily soluble in water. As a consequence, their solutions can be prepared in about $30 \mathrm{~min}$. The method is found to be working satisfactorily for the determination of sulfur dioxide in sugar samples and an air sample giving results (table) which are not only comparable with the results of sulfur dioxide determined using official methods [20, 27], but are also reproducible as revealed by the values of the statistical parameters (standard deviation, $t$ test, and $F$ test). Therefore, the method could be employed for the determination of sulfur dioxide either as an independent or a complimentary method [20, 27]. However, the method suffers from a low sensitivity when compared to the official methods [20,27], and the technique described in this paper requires knowing the precise concentration of hydrogen peroxide, which is very unstable in storage. This could be a compromise, because the new method involves safe and easily washable chemicals when compared to chemicals such as indicators $[22,30]$ and rosaniline hydrochloride [20, 27] used in other established [22, 30] and official methods [20, 27]. Obviously, such methods do require strict control of the $\mathrm{pH}$. In addition, rosaniline hydrochloride used in official methods $[20,27]$ is a known toxic chemical [21] and requires a longer period of time for the preparation of its solution [20]. 


\section{ACKNOWLEDGMENTS}

We are grateful to the Editorial Board of the journal and the referees for their valuable and very useful suggestions. Our sincere thanks to Dr. M. Mahadevaswamy and Mr. Sadashivamurthy (SJCE, Mysore) for providing the air-trapped sample and related discussions, Dr. K.N. Gurudatta and Dr. M.N. Manjunath (CFTRI, Mysore) for useful discussions on the analysis of the samples for sulfur dioxide using the official volumetric method [29], and Dr. M.D. Gowtham and Dr. B.M. Mohan (Director of Forensic Science Lab. Bangalore) and Dr. N. Balsubramanian (IIT, Madras) for their keen interest and encouragement.

\section{REFERENCES}

1. Laila, A., Talanta, 1989, vol. 36, no. 11, p. 1145.

2. Molyan, J.G., Bowes, F.W., and Pappin, W.J., J. AOAC Int., 1986, vol. 69, no. 1, p. 11.

3. Azeredo, C.M.N., Araki, K., Toma, H.E., and Angnes, L., Anal. Chim. Acta, 1999, vol. 387, no. 2, p. 175.

4. Coker, L.E., J. AOAC Int., 1986, vol. 69, no. 1, p. 8.

5. Solymosi, F. and Varga, A., Anal. Chim. Acta, 1957, vol. 17, p. 608.

6. Jackson, D.T. and Parsons, J.L., Ind. Eng. Chem. Anal. Ed., 1937, vol. 9, no. 1, p. 14.

7. Marsos, L. and Folyoirat, M.K., Chem. Abstr., 1958, vol. 52, p. 1166.

8. Yogendra Kumar, M.S., Gowtham, M.D., Mahadevaiah, and Nagendrappa, G., Anal. Sci., 2006, vol. 22, p. 757.

9. Geetha, K. and Balasubramanian, N., Microchem. J., 2000, vol. 65, no. 1, p. 45.

10. Scaringelli, F.P., Saltzman, B.E., and Frey, S.A., Anal. Chem., 1967, vol. 39, no. 14, p. 1709.

11. Agarwal, S.K.D. and Upadhayaya, S.K., Abstracts of Papers, STAI 44th Annual Convention, 1980, p. 57.

12. Meng, H., Wu, F., He, Z., and Zeng, Y., Talanta, 1999, vol. 48 , no. 3, p. 571.

13. Guoquam, G., He, X., and Heraigoing, W., Anal. Lett., 1995 , vol. 28 , no. 5 , p. 909.
14. Tavares Araccjo, C.S., Lirade Carvalho, J., Ribeiro Mota, D., De Araccjo, C.L., and Coelho, N.M.M., Food Chem., 2005, vol. 92, no. 4, p. 765.

15. Buerman, D.R. and Moloan, C.E., Anal. Chem., 1962, vol. 34, no. 3, p. 319.

16. Bruno, P., Caselli, M., Di Fano, A., and Traini, A., Analyst, 1979, vol. 104, p. 1083.

17. Segundo, M.A. and Rangel, A.O.S.S., Anal. Chim. Acta, 2001, vol. 427 , no. 2, p. 279.

18. Singla, M.L., Singh, M., Walia, M.S., Singla, S., and Mahapatra, P.K., Food Chem., 2006, vol. 97, no. 4, p. 737.

19. Burroughs, L.F. and Sparks, A.H., Analyst, 1961, vol. 86, p. 381.

20. ICUMS Method Book, Norwich: ICUMSA, 1994, GS233.

21. Clark, G.L. and Hawley, G.G., The Condensed Chemical Dictionary, New York: Van Nostrand Reinhold, 1972.

22. Gyathri, N. and Balasubramanian, N., J. AQAC Int., 2001, vol. 84, no. 2, p. 1065.

23. Emeleus, H.J. and Sharpe, A.G., Modern Aspects of Inorganic Chemistry, New Delhi: Universal Book Stall, 1989, 3rd ed.

24. Sandell, E.B., Colorimetric Determination of Traces of Metals, New York: Interscience, 1959, vol. 3.

25. Remy, H., Treatise on Inorganic Chemistry, Amsterdam: Elsevier, 1956, vol. 2.

26. Vogel's Text Book of Quantitative Chemical Analysis, Mendham, J., Denny, R. C., Barner, J. D., and Thomas, M. J. K., Eds., Delhi: Pearson Education, 2004, 6th ed.

27. Official Methods of Analysis of the Association of Official Analytical Chemists, Arlington: AOAC, 1984, 14th ed.

28. Rose, J., Advanced Physico-Chemical Experiments, London: Pitman, 1964.

29. Horwitz, W., Official Methods of Analysis of AOAC International, Gaithersburg: AOAC Int., 17th ed.

30. Pandurangappa, M., and Balasubrmanian, N., Analusis, 1996, vol. 24, p. 225. 